\title{
The role of family communication and parents' feeding practices in children's food preferences
}

\author{
Authors: Siril Alm, Svein Ottar Olsen and Pirjo Honkanen
}

\begin{abstract}
This study used Family Communication Patterns Theory (FCPT) to explore how familydinner-related communication takes place and how parents' feeding practices may be associated with children's preferences for dinner meals. The sample consisted of 12 dyads with seven- and eight-year-old Norwegian children and their parents. In-depth photo interviews were used for collecting data. Interview transcripts and photographs were examined through content analysis. Results indicated that most families were conversation oriented, and communication tended to shift from consensual during weekdays to pluralistic at weekends. On weekdays, the dinner menu was often a compromise between children's preferences and parents' intentions to provide quick, healthy dinner options for the family. To a greater extent at weekends, children were allowed to choose dinner alternatives for the entire family. Restriction of unhealthy dinner alternatives was the practice most used to control children's diets and, in fact, might explain children's high preferences for unhealthy dinner alternatives. Results underline the importance of giving children control of what they eat and being responsive to children's preferences while guiding them towards healthy dinner alternatives rather than using force and restriction. From a more theoretical perspective, this study explored how FCPT could be combined with theories about parents feeding practices to understand meal preferences and choices among young children and their families, and how time and situation (context) influence families' communication patterns and feeding practices in their homes.
\end{abstract}

Keywords: Dinner; Meal; Reinforcement; Context; Qualitative; Photograph

Classification: Research paper

Abbreviations: FCPT, Family Communication Theory; NSD, Norwegian Social Science Data Services; SFO, Skole Fritids Ordning; 


\section{Introduction}

According to the Norwegian Directorate of Health (2011), many children's diets contain energy-dense food with too much sugar, salt and saturated fat. The family's food environment plays a major role in a child's food consumption (Bassett, Chapman, \& Beagan, 2008; Birch \& Davison, 2001; Kral \& Rauh, 2010). Parents determine which foods and how much food children can access, and they serve as models for their children's food choices through their own food attitudes, preferences and behaviours (Birch, Savage, \& Ventura, 2007). Conversely, children influence their parents' food choices by expressing their preferences, negotiating, persuading, making demands and refusing to eat the foods their parents serve (Bassett et al., 2008; Holsten, Deatrick, Kumanyika, Pinto-Martin, \& Compher, 2012; Nørgaard \& Brunsø, 2011). Indeed, several studies have shown that the more influence children have, the less healthy their food choices tend to be (Papaioannou et al., 2013).

Dinner is normally the day's largest meal, providing more important nutrients than other meals (Gillman et al., 2000). It is also the activity which parents and children spend most time together (Bugge \& Almås, 2006). Still, surprisingly little research has described how family members influence one another's food consumption in home-dinner contexts (Fulkerson, Neumark-Sztainer, \& Story, 2006; Neumark-Sztainer, Hannan, Story, Croll, \& Perry, 2003), compared with other contexts such as snacking (e.g. Blissett, 2011; Melbye, Øgaard, \& Øverby, 2013). Snacks tend to be more informal and individualistic than collective family meals (Marshall \& O’Donohoe, 2010), which are more often compromises between individual preferences and different goals among family members (Nørgaard \& Brunsø, 2011). We suggest that the process and outcome of family communication and feeding practices might differ between family dinners prepared at home and 'individual food', such as snacks, fruit and drinks, since conflicting interests are more likely to occur for family meals. Thus, the purpose of this study is to explore how family-dinner-related communication occurs and how parents' feeding practices might be associated with children's food preferences. The study uses Family Communication Pattern Theory (FCPT) (Koerner \& Schrodt, 2014) and constructs from other studies on parents' feeding practices (Vollmer \& Mobley, 2013) as a theoretical foundation to explain children's preferences about food consumed as dinner. To our knowledge, this is the first study to explore how parents' feeding practices relate to families communication orientation. Thus, this study contributes to previous research about how those patterns may interact and influence children's food preferences. 


\section{Theoretical framework}

A preference is the choice of one item over another and consists of both affective and cognitive associations towards the item (Zeinstra, Koelen, Kok, \& de Graaf, 2007). Children tend to express their preferences in emotional terms such as 'love' and 'hate', compared with adults who employ more attitudinal terms such as 'like' and 'don't like' (Wiggins, 2014). At birth, children have innate genetic predispositions which cause them to prefer sweet and salty tastes and to reject sour and bitter tastes (Birch, 1999; Birch \& Davison, 2001). Young children have been found to prefer food with soft textures, while older children prefer crispy and hard textures (Zeinstra et al., 2007). Zeinstra and colleagues (2007) argued that taste, rather than texture, determines food preferences as children become older. Studies on children's preferences in specific dinner dishes are scarce compared with those on fruit and vegetable preferences. Zeinstra and colleagues (2007) found that most children, aged 4-12, tended to prefer soft, high-energy foods, such as pancakes and French fries, and that older children (7-12 years) tended to add preferences for meat and composite dishes, such as pizza and vegetable pie. Nevertheless, vegetables ranked low in children's choices of food (Zeinstra et al., 2007). Additionally, children's preferences in meals and other foods are also influenced by availability, culture and traditions (Birch et al., 2007).

Family Communication Patterns Theory (FCPT), as one of the most frequently applied theories of family communication, reflects important values and beliefs families have about themselves and their relationships (Koerner \& Schrodt, 2014). According to FCPT, families who tend to focus on objects and discuss how family members conceive them are conversation orientated. Families who tend to define objects for their children and emphasise obedience to authority figures are conformity orientated. By using median splits between conversation and conformity orientations, four family types have been described: consensual, pluralistic, protective and laissez-faire. Consensual families are high in both conversation and conformity orientations. In these families, parents are very interested in what their children have to say on a number of issues, while at the same time, they consider themselves the final decision makers. They resolve disagreements by listening to their children and spend time and effort explaining their values, beliefs and decisions so that their children understand the reasoning behind their decisions. Pluralistic families are high in conversation orientation and low in conformity orientation. These parents do not feel a need to be in control of their children, to make decisions for them or to agree with their decisions. Opinions are openly discussed and evaluated based on argumentative support rather than on who promotes the argument. Protective families are 
low on conversation orientation and high on conformity orientation. These families stress obedience to authorities and discuss few matters within the family. Parents tend to make decisions for the children and see little value in explaining their reasons to their children. The final communication type is laissez-faire, which is low in both orientations. These families communicate little with one other, and the parents tend to believe that all family members should be able to make their own decisions. In contrast to other families, parents show little interest in their children's decisions; therefore, conflicts are rare.

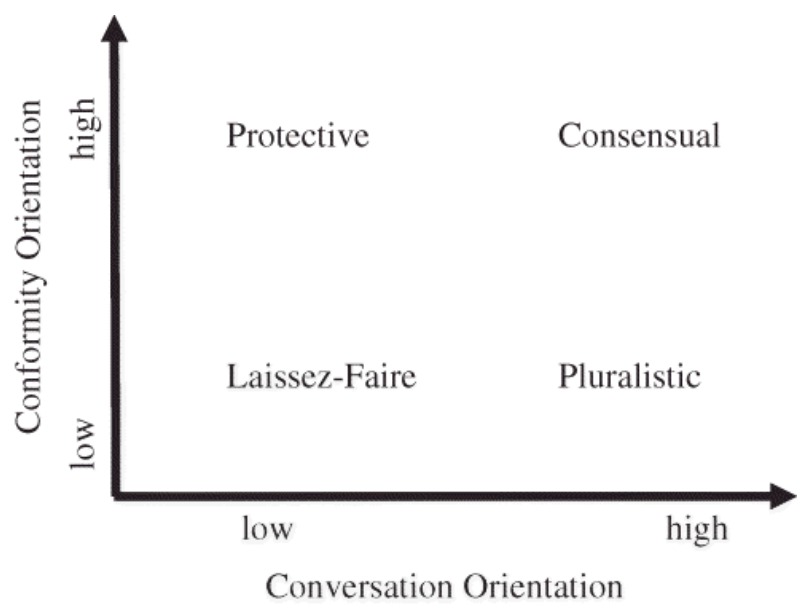

Figure 1: Four family types created by conversation and conformity orientation (Koerner \& Schrodt, 2014).

Multiple studies have agreed that families with high conversation orientation have children who influence their parents' purchases more and have more independent consumption perspectives, compared to families with high conformity orientation (Bassett et al., 2008; Caruana \& Vassallo, 2003; Nørgaard, Brunsø, Christensen, \& Mikkelsen, 2007; Olsen \& Ruiz, 2008). Conversation oriented families are traditionally described as concerned with both stating and explaining their opinions and actions (Koerner \& Schrodt, 2014). A study by Nørgaard and Brunsø (2011) challenged this traditional definition in regard to food-related research. Their study showed that most families practised conversational communication by discussing simple food-related issues with one another, for instance, stating preferences and opinions, but rarely explained their motivations for and barriers to their food preferences. Olsen and Ruiz (2008) found that teenagers in conversational families seemed to have greater influence on family dinner decisions, as compared to conformity families, because they often discussed dinner options and health consequences with their parents. 
Previous research emphasises that individual food preferences and choices differ across time, situations and context (Marshall \& O’Donohoe, 2010; Meiselman, Johnson \& Crouch, 2000). Parents' feeding practices are described as goal-directed behaviours with specific content that may reinforce parents' influence on children's diets (Birch et al., 2007; Vollmer \& Mobley, 2013). As opposed to FCPT, which presents the family members' static values (Koerner \& Schrodt, 2014), feeding practices may change in different contexts (Vollmer \& Mobley, 2013). Thus, this study's theoretical approach is to explore if families have different goals in different contexts, and to investigate how this may influence parents' communication patterns and feeding practices. For example, is it possible for parents to practice consensual oriented communication during busy weekdays, but be more pluralistic oriented during the weekends when they have more time for grocery shopping and cooking. Thus, an integration of time, situation or context in our study may open up for a broader understanding of how family communication patterns interact with family feeding practices in children's food preferences or choices.

Some of the most common feeding practices are parents' use of restriction, rules, rewards, pressure, arguments, disguising food and providing a nice atmosphere during meals. Restricting children's access to a preferred food is a feeding practice often applied by parents (Rollins, Loken, Savage, \& Birch, 2014a). Studies have indicated that restriction tends to increase preferences for the restricted food and might lead to overeating behaviour when that food is made available. Parents' use of rules, such as finishing everything before a second serving, is often presented as a restrictive strategy (Hart, Bishop, \& Truby, 2002). Giving attention and verbal praise or offering non-food rewards such as stickers and toys to reward children's positive behaviour is reported to increase their willingness to try unfamiliar foods (Horne et al., 2011) or eat healthy food (Puhl \& Schwartz, 2003). Offering food rewards, such as dessert, have been found to increase children's preferences for the food reward and decrease preferences for the targeted food (Birch, Marlin, \& Rotter, 1984). Pressuring children to eat food they do not like, or eat more food than they want, leads to aversion for that food (Sleddens et al., 2014). Argumentative practices, such as reminding children to finish their vegetables (Khandpur, Blaine, Fisher, \& Davison, 2014), disguising healthy food in dinner dishes (Peters, Parletta, Lynch, \& Campbell, 2014) and fostering a happy, relaxed atmosphere during family meals (Sleddens et al., 2014) have been seen as helpful strategies in improving children's diets as well. 
Linking parents’ reinforcing behaviour with FCPT, Moschis, Moore and Smith (1984) found that parents with pluralistic patterns were more likely to use positive reinforcements, such as rewards, and that protective parents were more likely to use negative reinforcements, such as pressure, when compared with other parents. Parents who emphasise consensual communication are more likely to use both positive and negative reinforcements and to present arguments that explain reasons behind behaviours. Controversially, laissez-faire parents do not communicate much with their children and are less likely to use food reinforcements.

\section{Methods}

Our targeted age group was children of seven and eight. This age group is particularly interesting to study because they are experiencing major changes both cognitively and socially (John, 1999). At seven and eight, children are becoming more interested in food, grocery shopping, cooking and eating, and neophobic tendencies have declined (Marotz, 2011).

Previous studies on FCPT tended to use survey methodology (Schrodt, Witt, \& Messersmith, 2008). Baiocchi-Wagner and Talley (2012) argue that the traditional measuring instruments for FCPT may be too general for studying domain-specific outcomes since all family communication might not be equal. They suggest that some families might be conversation oriented on a range of topics, but consider food and health a private issue not discussed with one another. In addition, surveys have been proven to be especially challenging for research with children younger than eight because of their less developed cognitive and expressive skills (Borgers, de Leeuw, \& Hox, 2000). Thus, we employed a qualitative explorative design for this study (Patton, 2002). Visual ethnographic methods, employing photographs and pictures, are considered a most useful research approach for prompting children's views (Davis, 2010; Johansson et al., 2009). We chose in-depth photo interviews as an exploratory approach. This method actively engaged children in photographing their environments, and the pictures were used as a basis for conversations between the researcher and the child (Zartler \& Richter, 2012). This approach helps children verbalise their thoughts and overcome the discomfort of being interviewed by an adult stranger. In addition to interviewing the children, we interviewed their parents to obtain fuller understanding of their communication orientation and feeding practices. 


\section{Recruitment process}

Before we recruited families, the Norwegian Social Science Data Services (NSD, 2013) approved the study. The Norwegian after-school programme, Skole Fritids Ordning (SFO) for first- to fourth-graders in primary school, is municipal and voluntary child care, paid for by parents who need it (Tromsø municipality, 2014). We approached all 79 second-graders at two SFOs in Tromsø, Norway. The only recruitment criterion was that the child be seven or eight years old. With permission from the school administration, we personally informed the children about the study and handed them an information letter in Norwegian, with a consent form, to take home to their parents. The information letter emphasised how personal data would be stored and used, and that participation was voluntary. Parents were advised to discuss participation with their children before returning the consent form. If a family participated, their child could keep the digital camera as an incentive.

Fourteen families volunteered, with the final sample consisting of twelve families with seven girls and five boys. All informants were homogeneous in terms of origin (Norwegian cultural background), and all came from a two-parent household. However, some different family situations with reference to the biological relationship with the child were found (see table 1). The sample represents a broad variety of education levels. The average household income level ( $€$ 132.000) can be described as above average compared to official Norwegian statistics ( $€$ 92.000) (Statistics Norway, 2013). This might be explained by the fact that each informant family had two incomes. Family characteristics were collected both during interviews and follow-up telephone calls.

\section{Table 1}

Family characteristics on the study's sample

\begin{tabular}{|c|c|c|c|c|c|c|c|c|c|c|}
\hline 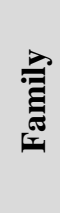 & 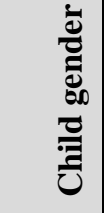 & 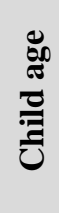 & 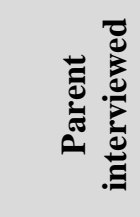 & 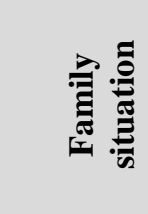 & 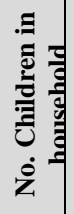 & 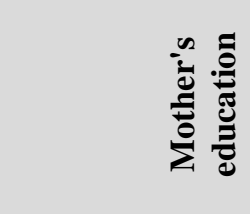 & 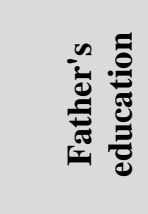 & 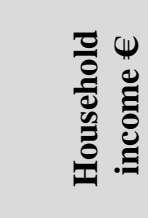 & لَّ & لِّ \\
\hline A & Girl & 7 & Mother & $\begin{array}{l}\text { Primary } \\
\text { family }\end{array}$ & 2 & $\begin{array}{l}4-5 \text { y. college/ } \\
\text { university }\end{array}$ & N/A & 131.000 & $\begin{array}{l}\text { Working } \\
\text { full time }\end{array}$ & N/A \\
\hline B & Girl & 7 & Mother & $\begin{array}{l}\text { Primary } \\
\text { family }\end{array}$ & 2 & $\begin{array}{c}<5 \text { y.college/ } \\
\text { university }\end{array}$ & N/A & 96.000 & $\begin{array}{l}\text { Working } \\
\text { full time }\end{array}$ & N/A \\
\hline $\mathrm{C}$ & Girl & 8 & Mother & $\begin{array}{l}\text { Foster } \\
\text { family }\end{array}$ & 3 & $\begin{array}{l}\text { High school/ } \\
\text { trade certificate }\end{array}$ & N/A & 102.000 & $\begin{array}{l}\text { Working } \\
\text { part time }\end{array}$ & N/A \\
\hline
\end{tabular}




\begin{tabular}{|c|c|c|c|c|c|c|c|c|c|c|}
\hline D & Boy & 7 & $\begin{array}{l}\text { Mother \& } \\
\text { Father }\end{array}$ & $\begin{array}{l}\text { Primary } \\
\text { family }\end{array}$ & 4 & $\begin{array}{c}<5 \text { y.college/ } \\
\text { university }\end{array}$ & $\begin{array}{l}\text { High school/ } \\
\text { trade } \\
\text { certificate }\end{array}$ & 120.000 & $\begin{array}{l}\text { Working } \\
\text { full time }\end{array}$ & $\begin{array}{l}\text { Working } \\
\text { full time }\end{array}$ \\
\hline E & Girl & 7 & Mother & $\begin{array}{l}\text { Primary } \\
\text { family }\end{array}$ & 2 & $\begin{array}{l}\text { High school/ } \\
\text { trade certificate }\end{array}$ & N/A & 54.000 & $\begin{array}{l}\text { Long } \\
\text { term sick } \\
\text { leave }\end{array}$ & N/A \\
\hline $\mathrm{F}$ & Girl & 7 & Mother & $\begin{array}{l}\text { Secondar } \\
\text { y family }\end{array}$ & 4 & $\begin{array}{c}\text { High school/ } \\
\text { trade certificate }\end{array}$ & N/A & 359.000 & Student & N/A \\
\hline G & Girl & 7 & $\begin{array}{l}\text { Mother \& } \\
\text { Father }\end{array}$ & $\begin{array}{c}\text { Primary } \\
\text { family }\end{array}$ & 3 & $\begin{array}{l}\text { High school/ } \\
\text { trade certificate }\end{array}$ & $\begin{array}{l}\text { High school/ } \\
\text { trade } \\
\text { certificate }\end{array}$ & 102.000 & $\begin{array}{l}\text { Working } \\
\text { full time }\end{array}$ & $\begin{array}{l}\text { Working } \\
\text { full time }\end{array}$ \\
\hline $\mathrm{H}$ & Boy & 8 & Mother & $\begin{array}{l}\text { Secondar } \\
\text { y family }\end{array}$ & 5 & $\begin{array}{c}\text { 4-5 y. college/ } \\
\text { university }\end{array}$ & N/A & 96.000 & $\begin{array}{c}\text { Maternity } \\
\text { leave }\end{array}$ & N/A \\
\hline I & Boy & 7 & $\begin{array}{l}\text { Mother \& } \\
\text { Father }\end{array}$ & $\begin{array}{l}\text { Primary } \\
\text { family }\end{array}$ & 2 & $\begin{array}{l}4-5 \text { y. college/ } \\
\text { university }\end{array}$ & $\begin{array}{l}\text { 4-5 y. college } \\
\text { / university }\end{array}$ & 84.000 & $\begin{array}{l}\text { Working } \\
\text { full time }\end{array}$ & $\begin{array}{l}\text { Working } \\
\text { full time }\end{array}$ \\
\hline $\mathrm{J}$ & Boy & 8 & $\begin{array}{l}\text { Mother \& } \\
\text { Father }\end{array}$ & $\begin{array}{l}\text { Primary } \\
\text { family }\end{array}$ & 2 & $\begin{array}{l}\text { High school/ } \\
\text { trade certificate }\end{array}$ & $\begin{array}{l}\text { High school/ } \\
\text { trade } \\
\text { certificate }\end{array}$ & 107.000 & $\begin{array}{l}\text { Working } \\
\text { full time }\end{array}$ & $\begin{array}{l}\text { Working } \\
\text { full time }\end{array}$ \\
\hline K & Boy & 7 & Mother & $\begin{array}{c}\text { Primary } \\
\text { family }\end{array}$ & 1 & $\begin{array}{c}\text { 1-3 y. college/ } \\
\text { university }\end{array}$ & N/A & 191.000 & $\begin{array}{l}\text { Working } \\
\text { full time }\end{array}$ & N/A \\
\hline $\mathrm{L}$ & Girl & 8 & $\begin{array}{l}\text { Mother \& } \\
\text { Stepfather }\end{array}$ & $\begin{array}{l}\text { Secondar } \\
\text { y family }\end{array}$ & 4 & $\begin{array}{c}\text { 1-3 y. college/ } \\
\text { university }\end{array}$ & $\begin{array}{c}1-3 \mathrm{y} . \\
\text { college/ } \\
\text { university }\end{array}$ & 138.000 & $\begin{array}{l}\text { Working } \\
\text { full time }\end{array}$ & $\begin{array}{l}\text { Working } \\
\text { full time }\end{array}$ \\
\hline
\end{tabular}

\section{Data collection}

Data were collected in February and March 2013. After the parents had given their written consent, the fieldworker (SA) met the children at SFO to inform them further about the study and to collect their consent forms. Each child received a digital camera and was taught how to use it. To investigate whether the children's diet varied according to different contexts (weekend/weekdays), we asked them to photograph their dinner meals during one week. They were asked to photograph according to the following topics: 'Food we eat for dinner'; 'Persons I eat dinner with'; 'Persons who prepare dinner at home'; 'Shopping for dinner with my family'. No limitation to the number of photographs was given. After one week of photographing, the fieldworker met each child separately for an interview at SFO. Interviews were conducted individually in a closed classroom, a familiar setting for the child (Clark \& Moss, 2001). The photographs were downloaded to a computer and viewed chronologically during the interview. All interviews conducted for the study were audio recorded and transcribed verbatim.

The interview guide for children consisted of themes concerning children's food preferences (e.g. 'What kind of food do you prefer for dinner and why?'), family communication (e.g. 'Who decides what to have for dinner, and do you have something to say?') and feeding practices (e.g. 'What do your parents say or do if you don't finish your dinner?'). Additional questions were asked, depending on what the children said about their 
photographs. If children had difficulties expressing their food preferences, they were asked to grade the discussed foods from one to ten ( $1=$ strongly disliked; $10=$ strongly preferred). This grading was usually followed up with a question like 'Why do you like that so much?' Answers involving FCPT and feeding practices were often followed up with open-ended questions, such as 'How do you feel about that?' and 'Can you tell me more about that?' At the end of each interview, the children were asked if they had other information they wanted to tell the fieldworker. Interviews lasted an average of 48 minutes. The total collected number of photographs was 408, an average of 34 photographs per child.

The same evening or the day after the child interview, the fieldworker went to the child's home to interview the parent(s) who usually prepared dinner for the family. Generally, this was the mother. In five families, both parents were present since they felt equally responsible for family dinners. In a few cases the children were present during parts of the parent interview and were allowed to comment on what was said during the interview. Parents' responses did not seem to be influenced by the child's presence. The interview guide for the parents included themes similar to those for the children. The interviews began with asking the parents to describe an ordinary dinner on a weekday in their home, including a description of routines, contexts, feelings and food they often consumed for dinner. These descriptions then prompted the following questions (e.g. 'Have you had any conflicts with your child during dinner, and, if so, how do you resolve them?'). In addition, parents described their goals for their children's diets. During the interview, parents viewed their children's photographs on a computer, providing them an opportunity for their comments and interpretations of the images. The fieldworker did not disclose or reveal any information previously provided by the children. The parent interviews averaged 62 minutes. Immediately after the home visit, field notes were recorded to highlight the most interesting topics discussed during the visit and other impressions of the informants. All interviews were audio-recorded with the participants' permission.

\section{Data Analysis}

The audio files were transcribed by a hired professional. A single researcher (SA) then employed directed content analysis (Hsieh \& Shannon, 2005). For accuracy, the first stage involved checking the transcripts against the tape recordings. Transcripts and photographs were repeatedly read and studied to identify pre-determined and emerging themes and patterns deductively. Pre-determined themes were chosen based on the four communication patterns of FQPT (Koerner\& Schrodt, 2014), literature on parent's feeding practices (Vollmer \& Mobley, 2013) and children’s food preferences (Zeinstra et al., 2007). The themes which emerged during 
the analysis were the children's wish of keeping food separated on the plate and being in control, the distinction between food eaten at weekdays and weekends, providing children choices and cooking together. The emerging themes will be presented and discussed in the following chapters. Major topics, as well as confusing and conflicting data, were discussed with coauthors and other researchers. The images on the photographs and information attached to the digital photo files, such as the date and time of day, proved to be a valuable source of information. If for example the child told us that they did not eat dinner one day, a submitted photograph with a dinner plate taken on the discussed day documented the opposite evidence. Photographs with the same motive or photographs irrelevant to the study were excluded. All the transcripts and 259 of the 408 photographs were then uploaded to Nvivo 10 qualitative data analysis software (2012) to be organised and coded. Statements concerning the most mentioned foods and dishes were explored and identified, employing the Word Frequency Function and Text Search Queries in NVivo 10. During this process, some themes tended to cluster, revealing data patterns. The last stage was to prepare a table of the final themes for analysis, which provided data on both predefined and emerging themes related to the selected concepts. Through this approach, the transcripts and photographs underwent a hermeneutic process which allowed exploration of the data in both parts and wholes, leading towards interpretations.

\section{Results}

In the following, results from the photo interviews are presented. To protect confidentiality, quotations from informants are labelled with letters from A-L, indicating a specific family (see table 1). Ellipses marks in parentheses indicate that part of the sentence has been deleted. Comments in parentheses describe anonymous information from the informant. A number in parentheses after a result indicates how many of the respondents the result in question was based upon.

\section{Children's dinner preferences}

Analysis from transcripts, photographs, Word Frequency Reports and Text Search Queries from NVivo 10 showed that the children's preferences were largely guided by taste. While talking about their preferred foods, phrases like 'I love', 'I like' and 'my favourite' were often used; additionally, they assigned the food ten points (or more). Innate genetic predispositions seemed to guide preferences in this age group: sweet food, like pancakes, was a favourite. 
Interviewer: How many points do you want to give pancakes?

- Ten.

Interviewer: (...) why are pancakes so great?

-Because they have sugar inside. And because the actual pancake tastes so good. (Girl, L)

Textures and cooking methods significantly influenced children's preferences for vegetables. Both children and parents described children's preferences towards raw or lightly cooked vegetables. Children preferred vegetables that provided a crunchy 'munch effect', especially carrots, but also other vegetables such as broccoli, sweet peas, red peppers and salad.

- We use carrots a lot (...). Sometimes we eat them raw or lightly cooked. They must not be too much boiled, then [girl informant] will not have them. Actually she likes them best raw. If they are cooked, they must still be crunchy. (Mother, A)

Few dishes were mentioned as less preferred. Children were more concerned about specific ingredients or parts of the dish. For example, they often explained that they refused to eat or did not like the dish if it contained potatoes, onions, tomatoes, mushrooms or corn. Phrases like 'I hate' and 'I don't like' were often used, along with giving the food a one-point rating. Several children $(\mathrm{N}=8)$ tended to have an aversion towards food that was mixed together. Parents accidentally blending food on a child's plate often caused an argument between child and parents, even causing the child to refuse the food. One girl explained that when her mother poured gravy over carrots, the combination caused a different, unwanted taste, leading to refusal of the carrots.

- I'm not so used to having gravy covering the carrots (...) my mom just poured it on. Interviewer: (...) you don't like the food when it's being mixed like that?

- (...) not when there is gravy on top of the carrots.

Interviewer: Why do you think it's disgusting? You like both the gravy and the carrots?

- It tastes different. (Girl, F)

Separating food on the plate provided children opportunities to follow different eating strategies. Some children $(\mathrm{N}=2)$ first ate what they liked best, followed by what they liked less, 
thus ensuring they got full with food they liked best. Other children $(\mathrm{N}=2)$ started with the food they liked less, saving the best for last.

-I usually eat the meat first, and then the rice and then the salad.

Interviewer: Why do you think it's like that?

- Because I like to eat the best first and the worst at the end. (Boy, I)

\section{Communicating about food}

Comparing interviews with children with interviews with their parents clarified that parents kept good records of which foods their children preferred, which foods they might refuse to eat and how they wanted the food served. Both children and parents stated that children had little influence on what was served at the dinner table (conformity orientation). Some families $(\mathrm{N}=9)$ reported that children could decide the menu one day each weekend and on special days, like their birthdays (conversation orientation), indicating a change of communication pattern depending on context. Parents explained that they usually had more time and were more willing to listen to their children's food desires during weekends as compared to busy weekdays. Parents emphasised the importance of democratic family processes and avoiding conflicts with the children (conversation orientation).

- I feel I have full (...) full authority in middle of the week, mostly (...). But on the weekends we usually agree on what we are going to make together (...).

Interviewer: How often does he get his way then?

- No, we're not having it up for discussion like that every day (....). I would say he may decide twice a week what we eat. (Mother, $\mathrm{K}$ )

Since children often wanted pancakes for dinner, parents emphasised that they would decide when to have pancakes (protective and consensual). Therefore, pancakes were often served as a surprise for the children.

-You could say that days when it fits with pancakes, we think, 'Now, today we have pancakes', so we let the kids choose. For we know that then there will be pancakes. And that's okay, because we had planned it. (Father, I)

Half of the parents tended to compromise with their children and adjusted meals so they corresponded with children's preferences (consensual). This was illustrated in many ways. As one example, a mother explained how she made her children eat Mølje, a traditional Norwegian seafood dish traditionally served with cod roe, liver and boiled potatoes. However, in order to 
make her daughter eat the cod roe, the roe was served with French fries and salad because these foods were preferred by her daughter.

-We try to be careful (...) because little sister is pretty picky (....). On one of the photographs you will see that we have cod roe and French fries. And that's because she does not like cod roe. So to be sure she gets something that she really likes, we just get these kinds of strange combinations. (Mother, B)

Parents were very much aware that their children resented blended food, letting the children decide whether food should be mixed or not on the plate (consensual and pluralistic).

- (...) We try first to put it separate. First it's separate, and then he can choose whether we should mix it or not. (...) Sometimes he does, and sometimes he does not. (...) In my experience, he does not always eat it when it is completely mixed. (Father, I)

If specific dishes were served too often, children often got tired of them, and this could cause conflicts between parents and children. Parents often adjusted the meals to their children's preferences to avoid conflicts at the dinner table (consensual).

- I used to love cod, but now I'm tired of it.

Interviewer: How often do you have it then?

- We used to have it very often, but my mom has slowed down slightly, since I was a bit mad at her when she cooked it so often. (Girl, F)

The ingredients for tacos, one of the children's favourites, were always served in separate bowls, giving the children a choice of what to put in their tortilla wrap or taco shell (pluralistic). One mother reported that she began serving other dishes the same way. She emphasised that serving food in separate bowls allowed everyone to choose what they liked.

-Salad (...) it's a very easy solution to have the different bowls on the table, because everyone can choose what they like. It's somehow more festive that way. (Mother, L)

Conflicts between the parents and children arose since some children often felt that avoiding an argument with their parents was less important than eating food they did not like. Seven of the parents confirmed that their children sometimes refused to eat their dinner and that this often caused arguments at the dinner table. 
Interviewer: Did everyone like that soup?

- Yes (...) Except me.

Interviewer: (...) Did you eat something else then, when the others ate it?

- I only ate bread. With butter.

Interviewer: Did the adults say anything about it?

- They say that I must eat.

Interviewer: (...). Do you sometimes argue with them?

- Yes...

Interviewer: So ... what do you think about that?

- It's OK. (Boy, D)

Some parents $(\mathrm{N}=5)$ admitted that they sometimes served food they did not like or felt disgusted by, only because the children wanted it (pluralistic). Foods mentioned were sausages, tacos, pancakes, minced-meat products, meat pie, tomato soup, fish fingers and fish dumplings. The children did not seem aware of their parents' disgust, since the children never mentioned this in the interviews.

Interviewer: Who decided to have sausages for dinner that day?

- I think it was [brother of girl informant], actually.

Interviewer: What do you think of sausages for dinner?

- Terrible. It's not my favourite, so to speak.

Interviewer: So do you feel that you have to compromise with the children?

- Yes, we have to ... yes. (Mother, G)

Children employed different strategies for dealing with disliked foods. For example, four of the children did not like potatoes. This often caused arguments between parents and children, and some children were forced to eat potatoes (protective). Even though children did not like potatoes much, they often preferred them when served something they disliked more.

Interviewer: Did you eat any of that food?

- (...) I ate the potato.

Interviewer: Did you? But you said you did not like potato?

- Sometimes I like it.

Interviewer: Sometimes? Why do you sometimes and sometimes not?

- Because ... just because. Because... (Boy, D) 
Families with many children tended to be more conformity oriented than families with fewer children. Having many children simply made it difficult to respond to multiple requests from the family members. Parents knew which food was liked by their children and tried to avoid serving dishes which could cause refusal by the children.

Interviewer: Do you sometimes ask the children what they want for dinner? -

- Well, we have discovered that.... We then get 15 suggestions. And when you have five kids they often do not want the same food. So I have figured out that we simply do not ask them what they want. (Mother, $\mathrm{H}$ )

\section{Parents' feeding practices}

Even though feeding practices was mentioned in all interviews, more parents than children discussed the specific practices with the interviewer. As an example, restriction of food for controlling children's food consumption was discussed with all twelve parents in the sample, but only mentioned by seven children. The most common reasons for restriction were parents' wish to prevent children eating unhealthy food and lack of time to cook food the children wanted. To illustrate parents' use of restriction and conversation oriented communication, we describe Family $\mathrm{K}$ in more detail. The mother, the only parent of the sample who expressed true concern for her son's high weight, explained that she often had to restrict his access to food. His appetite often caused him to eat too large dinner portions and then ask for snacks shortly after meals. During the interview with the mother, her son entered the room several times asking for cookies and hot chocolate. The mother responded first by telling him he could get some later, but after a couple of new requests, she gave in and gave him a cookie. She explained that she usually gave him fruit when he made these kinds of requests, and that cookies and other unhealthy snacks were reserved for weekends. She further explained that if they did grocery shopping together, he was usually allowed to choose which cookies or soda they would buy for the weekend. Even though the mother expressed great concern for eating healthily on weekdays, she described a more liberal attitude for weekends when her son was more often allowed to choose what to have for dinner and to eat unhealthy snacks. It was evident that unhealthy snacks were usually present in the house, including weekdays, with the son's knowledge. 
Parents used different reasoning to persuade children to eat novel or less preferred foods. The use of rules, such as children not being allowed to refuse food before having tasted it at least once or eating a specific number of pieces, was used in several families $(\mathrm{N}=11)$.

- (...) when I say 'No, I do not like it', then dad usually says ... like 'Yes, you must ... you have to taste a bit'. And then I agree with that ... then I agree. For one can never say no to something you've never tasted before. (Boy $\mathrm{H})$

The use of rewards was less practised. Three parents mentioned using praise if children ate adequate amounts of dinner, and four parents sometimes offered fruit, yoghurt, chocolate and ice cream as a reward if the children finished their meals or ate foods they did not like. Eating dessert was most common when children dined at their grandparents' homes and when children with separated parents visited their fathers. Ice cream and other unhealthy options were most common in these contexts. One parent believed their children ate less for dinner to save room for dessert, while another believed that they ate more dinner to somehow deserve dessert. One boy admitted that he ate more for dinner if he got dessert.

Interviewer: But what do they say to make you eat potatoes?

- They say that I get dessert.

Interviewer: So ... what do you usually get for dessert, then?

- An apple. (Boy, D)

Use of pressure was less prevalent. Only one father (I) admitted that they sometimes withheld dessert as a punishment if the children refused to finish their meals. Sometimes parents felt they had to force their children to eat enough dinner. Force could be strong, like not allowing children to leave the table before they finished their plate or resemble encouragement, that is, putting more food on the plate than the children asked for.

- (...) If I know he's going to say he is full after one portion, I put on a little extra on the plate ... because I know that he is not going to ask for a second serving. (...).

There has been a few times where he refused to eat. Once we had salmon when he was younger. He refused to taste it, and he had to sit by the table until (...) he had tasted.

So he sat there for a while.... (Mother I)

- Even hummed a bit and picked the food and ... (Father, I)

- (...) And then he went to bed. (Mother, I) 
If children did not want to eat a specific food or dish, parents $(\mathrm{N}=4)$ often tried to reason with them, often arguing that the food was good for their health. This could entail an argument between children and parents, and sometimes parents gave in to their children's refusals.

Interviewer: What do you think about broccoli?

- It is not very good. But I have to eat it (...) At least one.

Interviewer: So ... what does Mom say when you have broccoli?

- That broccoli is healthy. But sometimes, when we have broccoli, I do not need to eat

it, since I'm so good at eating broccoli other times. (Girl, F)

Sometimes parents $(\mathrm{N}=2)$ disguised foods the children did not like, tricking them into eating it unknowingly. Children explained that some vegetables had bad, weird or bitter tastes. Many children had aversions towards onions, tomatoes, broccoli, corn, mushrooms and green peppers.

- We have found some recipes that we often use (...) we kind of have integrated more vegetables and other stuff that the kids don't like and can't see what's on the plate. It's somehow being inside the dish. (Mother, $\mathrm{H}$ )

When families had more time for cooking, children $(\mathrm{N}=8)$ sometimes participated in preparing the food. Most common was preparing tacos on Friday evenings. Children often helped chop the vegetables. Some children talked about the excitement of using a sharp knife.

Interviewer: But do you participate and help out in the kitchen when mom or [stepfather] cook?

-Depends what it is. When it's tacos I used to sometimes (...). I ask because it's fun to chop. (Girl, L)

\section{Discussion and conclusions}

This study explored how family-dinner related communication takes place and how parents' feeding practices might be associated with children's food preferences. In accordance with Wiggins (2014), our results confirmed that children often express their meal preferences with emotional terms like 'love' or 'hate', and traditional terms such as 'like', my favourite' and 'dislike'. Corresponding with former studies (Holsten et al., 2012), children in our sample explained that taste was the main driver for preferring food. The importance of texture for 
children's preferences was evident in consuming vegetables. For example, children seemed to prefer raw and lightly cooked vegetables, a finding that corresponds with studies indicating that children in this age group prefer food with crisp and hard textures (Baxter, Jack, \& Schröder, 1998; Szczesniak, 1972). Children’s preferences for soft textures, like pancakes, have earlier been associated with younger age groups (Zeinstra et al., 2007). Even though food texture was important for the children, our findings contradicted the research by Zeinstra and colleagues (2007), who argued that texture was more important than taste for this age group. Children in our sample explained that they preferred food because of good taste. Children often refused to eat dishes with bitter taste, such as unions and mushrooms, or disliked textures, such as soft vegetables. Another interesting finding in our study is the children's aversion towards mixed food and their wish to keep ingredients separated on the plate. Yet, to our knowledge, no studies have researched the reasons for this phenomenon. Children in our sample wanted to be in control of what they ate, and they wanted to make their own judgments about whether they liked foods or not. This is congruent with arguments from Szczesniak (2002), stating that humans want to be in full control of what they eat.

The results related to FCPT indicated a high conversation orientated communication pattern in most families (Koerner \& Schrodt, 2014). Even though both parents and children stated that children had little influence on the foods served on weekdays, photographs showed that children's preferred foods, like pancakes and spaghetti Bolognese, were mostly served on weekdays. Analysis of photographs illustrated that most dinners, independent of weekday, contained some level of compromise or children's influence. Most families practised communication that might be described as consensual during weekdays: parents tended to perceive their children's food desires, and discussed and compromised with the children to fulfil both parties' wishes, that is, the parents' wishes for healthy food and the children's wishes for preferred foods. During weekends, communication tended to be more pluralistic oriented since children were more often allowed to choose explicitly the food they wanted for dinner, with less parental interference. These findings correspond with those of Solér and Plazas (2012) who found in a Swedish sample that children have more influence on food consumed during weekends compared to other meals. They explained that this tendency corresponds with a prevalent Swedish non-authoritarian parenting style and the view of children as full members of society. Thus, such parents tend to give their children increased an influence on meals while time together and enjoyment are prioritized. Since Norway and Sweden are viewed as comparable neighbouring countries (Lindahl, 2011), we believe that our findings support Solér 
and Plazas (2012) arguments. In addition, our results indicate that the families' dinner choices tended to be unhealthier during weekends compared with weekdays -a finding which confirms that children with strong influence on family decisions tend to negatively affect the families' diets (Papaioannou et al., 2013). These findings also support Baiocchi-Wagner and Talley's (2012) argument that FCPT may be too general to understand families' communication patterns over time and across situations. However, families with many children tended to be more conformity oriented compared with families with fewer children. This finding indicates that families' communication patterns may change as more children are born into the family.

Results concerning communication also indicated that children exerted much more influence on family dinners than previously anticipated (Bassett et al., 2008; Caruana \& Vassallo, 2003; Nørgaard et al., 2007; Olsen \& Ruiz, 2008). Serving food that appealed to children's preferences was often more important than cooking healthy food and even more important than cooking food the parents themselves liked (Nørgaard \& Brunsø, 2011). Children influenced their parents by refusing to eat and by stating their preferences and food wants. They compromised by eating the number of pieces of less preferred food suggested by their parents or just ate the preferred parts of a dish. Parents kept fair records of the children's preferences and were highly inclined to adjust dinners to children's wants, similar to the study by Søndergaard and Edelenbos (2007). Parents employed multiple strategies to compromise with their children, such as cooking food the way children liked, serving food in separate bowls and serving unusual food combinations to accommodate both parties' preferences. The children's favourite, tacos, was always served in separate bowls. This provided children the opportunity to choose what they put in their taco shell or tortilla wrap, and indeed, having choices might explain their preference for tacos. Former studies have argued that being able to choose themselves makes children feel autonomic and makes them like the food that they choose (van der Horst, 2012; Altintzoglou et al., 2014). In our interpretation of the data, we suggest that giving children a choice between several healthy options may function as a beneficial feeding practice to improve children's diets.

The families' distinctions between weekdays and weekends confirm the assumption that feeding practices change according to context (Vollmer \& Mobley, 2013). Restriction for unhealthy food was the most common feeding practice during weekdays and shows that most parents practiced some aspects of protective communication. Our description of restriction in family K, gives us valuable information about how restriction occurs in natural contexts. Even though the parents were concerned about their son's weight, they bought and stored unhealthy 
food in the house with their son's knowledge. When the son constantly pestered for unhealthy snacks, the parents tended to give in. This kind of direct restriction might increase children's preferences for restricted food and might lead to overeating behaviour (Blissett \& Fogel, 2013). Our results support findings from a Swedish study which found that parents of children with high BMI tended to use restriction more than other parents (Nowicka, Sorjonen, Pietrobelli, Flodmark, \& Faith (2014).

Parents' use of food rules, such as always eating two pieces of every food item on the plate and not being allowed to say they did not like the food before they had tasted it, was an argumentative strategy. Children seemed to understand the logic behind these rules and tended to give in to their parents' suggestions. Considering literature concerning mere exposure to prevent food neophobia (Anzman-Frasca, Savage, Marini, Fisher, \& Birch, 2012; Pliner, 1982), we suggest that these arguments might benefit children if they eat unfamiliar or disliked food, as long as they understand the rules. Another argumentative strategy was to encourage consumption because the food was healthy. This strategy has been proven less effective since children's health concerns are limited (Berg, Jonsson, \& Conner, 2000; Honkanen, Olsen, \& Myrland, 2004).

Parents sometimes used verbal praise and/or fruit as a reward if their children finished their meals. Considering children's low intake of fruit (Norwegian Directorate of Health, 2011), using fruit as a reward might not seem inappropriate. However, parents should be aware that using food rewards can decrease children's preferences to the targeted food (Birch, Marlin, \& Kramer, 1982; Birch et al., 1984) limiting the chances they will consume that food when they choose foods more independently as they mature. To a limited extent, parents also used different kinds of pressure to make children eat more food than the children wanted. According to the literature, this is a common practice for our chosen age group (Pulley, Galloway, Webb, \& Payne, 2014). Our results are comparable with those of Orrell-Valente and colleagues (2007), who found that most children increased their food intake when parents used pressure, thus ignoring children's innate capacity to regulate energy intake. This may lead to overeating behaviour as they grow older since children are taught to continue eating after they are full. In addition, pressure strategies are argued to evoke lifelong cognitive aversions to the pressured foods because children associate them with negative eating experiences (Gregory, Paxton, \& Brozovic, 2011).

To increase children's consumption of vegetables, some parents prepared dishes that disguised vegetables. Thus, the children did not know they ate vegetables and were unable to 
become familiar with consuming vegetables. We know that modifying or masking healthy food has become widespread in recent years. Food companies produce foods that hide fruits and vegetables in other food dishes, such as pasta sauces and meat products (Peters et al., 2014). Celebrity chefs have promoted this strategy as well (Lapine, 2007; Oliver, 2014). Although this trend makes children's diets healthier, no evidence shows that children actually develop preferences for the hidden ingredients in the long run. If, for example, a child is used to eating pasta sauce with blended broccoli, the child is not more likely to consume broccoli when it is presented alone. Our findings indicate that modifying food is probably not the best strategy for improving children's preferences for vegetables.

During weekends, parents often included their children in dinner preparation. One of the children's favourites, tacos, was a typical dish on these occasions. Tacos were usually served on Fridays or on days when the family had time to prepare food together. These results correspond with findings from a Swedish study (Solér \& Plazas, 2012). Considering former studies that show cooking food together positively influences children's dietary patterns (Leech et al., 2014; van der Horst, Ferrage, \& Rytz, 2014), we suggest that cooking food together creates a happy, relaxed atmosphere (Sleddens et al., 2014) that may reinforce children's preferences for foods the family cooks together. Cooking food makes children feel empowered and proud (van der Horst et al., 2014); therefore, involving children in food preparation might be an effective strategy for encouraging children to eat healthy foods.

Results concerning the relationship between the different communication styles and parents' reinforcing feeding strategies differ to some degree from previous literature. Moschis and colleagues (1984) argued that positive reinforcements, such as rewards, are more likely used by pluralistic parents. Children in our study often had stronger influence on the choice of family dinners, especially during weekends (pluralistic communication), making rewarding behaviour unnecessary in such contexts. Negative reinforcement, such as pressure and force, has been argued as being most used by protective parents (Moschis et al., 1984). On the contrary, our results indicate that pluralistic and consensual parents employ such strategies to some degree as well. Results contradicting former literature thus imply important future research on FCPT and related feeding practices. These should be investigated with larger, more diverse samples in order to present more valid results. Considering previous literature, FCPT presents family members'values as static, while feeding practices represent goals being modified according to context (Koerner \& Schrodt, 2014; Vollmer \& Mobley, 2013). Our results indicate that both communication patterns and feeding practices may change according 
to context, since parents expressed different feeding values and goals for their children on weekends and weekdays. To our knowledge, these results are first to indicate that communication patterns might change according to context, a finding that warrants further research on FCPT in different contexts.

The present study is a small qualitative and exploratory study of twelve Norwegian families. Consequently, the results cannot be considered representative. Future research on FCPT and feeding practices should use larger and varied demographic samples and also combine other methods to confirm our findings. Our sample did not include one-parent households which could have produced more varied results. Single parents often have lower income (McDermott \&Stephens, 2010) than our sample, and we believe that a more diverse sample could show larger differences in the consumption -and communication patterns. As an example, children from low income families have been found to consume higher calorie foods compared with children from wealthier families (Buijzen, Schuurman \& Bomhof, 2008).

The finding that no subjects in our sample demonstrated laissez-fare communication patterns needs to be further researched with more representative samples. In addition, representative samples across different countries may give some indication whether cultural conditions may explain the absence of laissez-faire pattern for food-related communication (Rose, Boush \& Shoham, 2002). Another possible explanation of the lack of laissez-fare pattern is that families of today tend to be more democratic and communicate openly with each other. Thus, parents pay more attention to their children and their opinions (Nørgaard et al., 2007). It would also be interesting to investigate whether this is a domain-specific trend. Perhaps parents of young children feel highly responsible for their children's food consumption and, therefore, are more conversation oriented when it comes to food related communication, compared with communication about other topics. With the increasing number of secondary families (Seltzer \& Bianchi, 2013), future studies which use more representative samples should also investigate if non-biological parents communicate differently with the children compared with biological parents.

Since we first approached and informed children, rather than the parents, the children seemed highly motivated to participate in the study. The chosen age group appeared to fit our methodological approach of photo interviews. Children had no problem comprehending their task and managing the digital camera. In addition, the photographs helped children remember and articulate descriptions of the photographs, and the photographs helped them concentrate 
during the interviews. Through this method, children controlled the data and were respected as co-researchers, an approach known for increasing a study's reliability (Smith, Monaghan, \& Broad, 2002).

\section{Implications for caretakers}

Based on our results, some practical recommendations can be provided to parents and other caretakers responsible for feeding children:

$\checkmark$ Present vegetables raw or lightly cooked.

$\checkmark$ Serve food in separate bowls.

$\checkmark$ Discuss with the child what to have for dinner, but explain why you choose differently from what the child requests.

$\checkmark$ Limit the child's food choices to healthy food alternatives.

$\checkmark$ Encourage children to eat food because it is tasty, not healthy.

$\checkmark$ Only use food rules the child understands, such as always tasting food before rejecting it.

$\checkmark$ Avoid storing unhealthy food in the home and restrict the child's access to it.

$\checkmark$ Let children know what they eat. Do not disguise novel or previously refused food.

$\checkmark$ Prepare food with the child.

$\checkmark$ Praise children when they finish their food. Do not reward with food.

$\checkmark$ Do not pressure children to eat more than they would like.

$\checkmark$ Calorie rich food should be limited independently of the weekday.

\section{Acknowledgements}

The authors gratefully acknowledge the financial funding from The Research Council of Norway. 


\section{References}

Altintzoglou, T., Skuland, A. V., Carlehög, M., Sone, I., Heide, M., \& Honkanen, P. (2014). Providing a food choice option increases children's liking of fish as part of a meal. Food Quality and Preference, 39(0). doi: 10.1016/j.foodqual.2014.06.013

Anzman-Frasca, S., Savage, J. S., Marini, M. E., Fisher, J. O., \& Birch, L. L. (2012). Repeated exposure and associative conditioning promote preschool children's liking of vegetables. Appetite, 58(2), 543-553. doi: 10.1016/j.appet.2011.11.012

Baiocchi-Wagner, E. A., \& Talley, A. E. (2012). The Role of Family Communication in Individual Health Attitudes and Behaviors Concerning Diet and Physical Activity. Health Communication, 28(2), 193-205. doi: 10.1080/10410236.2012.674911

Bassett, R., Chapman, G. E., \& Beagan, B. L. (2008). Autonomy and control: The coconstruction of adolescent food choice. Appetite, 50(2-3), 325-332. doi:10.1016/j.appet.2007.08.009

Baxter, I. A., Jack, F. R., \& Schröder, M. J. A. (1998). The use of repertory grid method to elicit perceptual data from primary school children. Food Quality and Preference, 9(1-2), 73-80. doi: 10.1016/S0950-3293(97)00031-1

Berg, C., Jonsson, I., \& Conner, M. (2000). Understanding choice of milk and bread for breakfast among Swedish children aged 11-15 years: An application of the Theory of Planned Behaviour. Appetite, 34(1), 5-19. doi: 10.1006/appe.1999.0269

Birch, L. L. (1999). Development of food preferences. Annual Review of Nutrition, 19, 41-62.

Birch, L. L., Birch, D., Marlin, D. W., \& Kramer, L. (1982). Effects of instrumental consumption on children's food preference. Appetite, 3(2), 125-134. doi: $\underline{10.1016 / S 0195-6663(82) 80005-6}$

Birch, L. L., \& Davison, K. K. (2001). Family environmental factors influencing the developing behavioral controls of food intake and childhood overweight. Pediatric clinics of North America, 48(4), 893-907.

Birch, L. L., Marlin, D. W., \& Rotter, J. (1984). Eating as the" means" activity in a contingency: Effects on young children's food preference. Child Development, 55(2), 431-439. doi: http://www.jstor.org/stable/1129954 
Birch, L. L., Savage, J. S., \& Ventura, A. (2007). Influences on the development of children's eating behaviours: From infancy to adolescence. Canadian Journal of Dietetic Practice and Research, 68(1), 1-56.

Blissett, J. (2011). Relationships between parenting style, feeding style and feeding practices and fruit and vegetable consumption in early childhood. Appetite, 57(3), 826-831. doi: 10.1016/j.appet.2011.05.318

Blissett, J., \& Fogel, A. (2013). Intrinsic and extrinsic influences on children's acceptance of new foods. Physiology \& Behavior, 121(0), 89-95. doi:

10.1016/j.physbeh.2013.02.013

Borgers, N., de Leeuw, E., \& Hox, J. (2000). Children as Respondents in Survey Research: Cognitive Development and Response Quality 1. Bulletin de Méthodologie Sociologique, 66(1), 60-75. doi: 10.1177/075910630006600106

Bugge, A. B., \& Almås, R. (2006). Domestic dinner: Representations and practices of a proper meal among young suburban mothers. Journal of Consumer Culture, 6(2), 203228. doi: $10.1177 / 1469540506064744$

Buijzen M., Schuurman, J. \& Bomhof, E. (2008). Associations between children's television advertising exposure and their food consumption patterns: A household diary-survey study. Appetite 50(2-3), 231-239. doi:10.1016/j.appet.2007.07.006

Caruana, A., \& Vassallo, R. (2003). Children's perception of their influence over purchases: the role of parental communication patterns. Journal of Consumer Marketing, 20(1), 55-66. Doi: 10.1108/07363760310456955

Clark, A., \& Moss, P. (2001). Listening to young children: The mosaic approach. London: National Children's Bureau.

Davis, T. (2010). Methodological and design issues in research with children. In D. Marshall (Ed.), Understanding children as consumers (pp. 61-78). London: SAGE publications.

Fulkerson, J. A., Neumark-Sztainer, D., \& Story, M. (2006). Adolescent and parent views of family meals. Journal of the American Dietetic Association, 106(4), 526-532. doi: 10.1016/j.jada.2006.01.006

Gillman, M. W., Rifas-Shiman, S. L., Frazier, A. L., Rockett, H. R. H., Camargo, C. A., Field, A. E., Berkey, C. S., Colditz, G. A. (2000). Family dinner and diet quality among older children and adolescents. Archives of family medicine, 9(3), 235-240.

Gregory, J. E., Paxton, S. J., \& Brozovic, A. M. (2011). Maternal feeding practices predict fruit and vegetable consumption in young children. Results of a 12-month longitudinal study. Appetite, 57(1), 167-172. doi: 10.1016/j.appet.2011.04.012 
Hart, K. H., Bishop, J. A., \& Truby, H. (2002). An investigation into school children's knowledge and awareness of food and nutrition. Journal of Human Nutrition and Dietetics, 15(2), 129-140. doi: 10.1046/j.1365-277X.2002.00343.x

Holsten, J. E., Deatrick, J. A., Kumanyika, S., Pinto-Martin, J., \& Compher, C. W. (2012). Children's food choice process in the home environment. A qualitative descriptive study. Appetite, 58(1), 64-73. doi: 10.1016/j.appet.2011.09.002

Honkanen, P., Olsen, S. O., \& Myrland, Ø. (2004). Preference-based segmentation: a study of meal preferences among Norwegian teenagers. Journal of Consumer Behaviour, 3(3), 235-250. doi: 10.1002/cb.137

Horne, P. J., Greenhalgh, J., Erjavec, M., Lowe, C. F., Viktor, S., \& Whitaker, C. J. (2011). Increasing pre-school children's consumption of fruit and vegetables. A modelling and rewards intervention. Appetite, 56(2), 375-385. doi: 10.1016/j.appet.2010.11.146

Hsieh, H.-F., \& Shannon, S. E. (2005). Three Approaches to Qualitative Content Analysis. Qualitative Health Research, 15(9), 1277-1288. doi: 10.1177/1049732305276687

Johansson, B., Mäkelä, J., Roos, G., Hillén, S., Hansen, G. L., Jensen, T. M., \& Huotilainen, A. (2009). Nordic children's foodscapes: Images and reflections. Food, Culture and Society: An International Journal of MultidisciplinaryResearch, 12(1), 25-51.

John, D. R. (1999). Consumer socialization of children: A retrospective look at twenty-five years of research. Journal of Consumer Research, 26(3), 183-213. doi: $10.1086 / 209559$

Khandpur, N., Blaine, R. E., Fisher, J. O., \& Davison, K. K. (2014). Fathers’ child feeding practices: A review of the evidence. Appetite, 78(0), 110-121. doi: 10.1016/j.appet.2014.03.015

Koerner, A. F., \& Schrodt, P. (2014). An Introduction to the Special Issue on Family communication patterns theory. Journal of Family Communication, 14(1), 1-15. doi: $10.1080 / 15267431.2013 .857328$

Kral, T. V. E., \& Rauh, E. M. (2010). Eating behaviors of children in the context of their family environment. Physiology \& Behavior, 100(5), 567-573. doi: 10.1016/j.physbeh.2010.04.031

Lapine, M. C. (2007). The sneaky chef: simple strategies for hiding healthy foods in kids' favorite meals. Philadelphia: Running Press Book Publishers

Leech, R. M., McNaughton, S. A., Crawford, D. A., Campbell, K. J., Pearson, N., \& Timperio, A. (2014). Family food involvement and frequency of family dinner meals among Australian children aged 10-12\&\#xa0;years. Cross-sectional and longitudinal 
associations with dietary patterns. Appetite, 75(0), 64-70. doi:

10.1016/j.appet.2013.12.021

Lindahl, L. (2011) A comparison of family and neighborhood effects on grades, test scores, educational attainment and income-evidence from Sweden. The Journal of Economic Inequality 9(2), 207-226. doi: 10.1007/s10888-010-9144-1

Marotz, L. R. (2011). Children's dietary needs: nutrients, interactions and their role in health. In D. Kilcast \& F. Angus (Eds.), Developing children's food products (pp. 3-25). Cambridge: Woodhead Publishing Limited.

Marshall, D., \& O'Donohoe, S. (2010). Children and food. In D. Marshall (Ed.), Understanding children as consumers (pp. 167-183). London: SAGE publications.

McDermott, A. J. \& Stephens, M. B. (2010). Cost of eating: whole foods versus convenience foods in a low-income model. Family Medicine, 42(4), 280-284.

Meiselman, H. L., Johnson, J. L., Reeve, W., \& Crouch, J. E. (2000). Demonstrations of the influence of the eating environment on food acceptance. Appetite, 35(3), 231-237. doi: 10.1006/appe.2000.0360

Melbye, E. L., Øgaard, T., \& Øverby, N. C. (2013). Associations between parental feeding practices and child vegetable consumption. Mediation by child cognitions? Appetite, 69(0), 23-30. doi: 10.1016/j.appet.2013.05.005

Moschis, G. P., Moore, R. L., \& Smith, R. B. (1984). The impact of family communication on adolecent consumer socialization. Advances in Consumer Research, 11(1), 314-319.

Neumark-Sztainer, D., Hannan, P. J., Story, M., Croll, J., \& Perry, C. (2003). Family meal patterns: Associations with sociodemographic characteristics and improved dietary intake among adolescents. Journal of the American Dietetic Association, 103(3), 317322. doi: $10.1053 /$ jada.2003.50048

Nowicka, P., Sorjonen, K., Pietrobelli, A., Flodmark, C.-E., \& Faith, M. S. (2014). Parental feeding practices and associations with child weight status. Swedish validation of the Child Feeding Questionnaire finds parents of 4-year-olds less restrictive. Appetite, 81(0), 232-241. doi: 10.1016/j.appet.2014.06.027

NSD (2013). Norwegian Social Science Data Services. Retrieved 01.08.2014, from http://www.nsd.uib.no/nsd/english/index.html

NVivo qualitative data analysis software, QSR International Pty Ltd. Version 10, 2012 
Nørgaard, M. K., \& Brunsø, K. (2011). Family conflicts and conflict resolution regarding food choices. Journal of Consumer Behaviour, 10(3), 141-151. doi: 10.1002/cb.361

Nørgaard, M. K., Brunsø, K., Christensen, P. H., \& Mikkelsen, M. R. (2007). Children's influence on and participation in the family decision process during food buying. Young Consumers, 8(3), 197-216.

Oliver, J. (2014). Getting fresh with Jamie Oliver. An all-natural, make-ahead sauce recipe so stealth it packs in seven veggies Retrieved 01.08.2014, from http://www.parenting.com/article/healthy-pasta-recipes\#block-facebook-commentsfacebook-comments

Olsen, S. O., \& Ruiz, S. (2008). Adolescents’ influence in family meal decisions. Appetite, 51(3), 646-653. doi: 10.1016/j.appet.2008.05.056

Orrell-Valente, J. K., Hill, L. G., Brechwald, W. A., Dodge, K. A., Pettit, G. S., \& Bates, J. E. (2007). “Just three more bites”: An observational analysis of parents' socialization of children's eating at mealtime. Appetite, 48(1), 37-45. doi: 10.1016/j.appet.2006.06.006

Papaioannou, M. A., Cross, M. B., Power, T. G., Liu, Y., Qu, H., Shewchuk, R. M., \& Hughes, S. O. (2013). Feeding style differences in food parenting practices associated with fruit and vegetable intake in children from low-income families. Journal of Nutrition Education and Behavior, 45(6), 643-651. doi: 10.1016/j.jneb.2013.05.007

Patton, M. Q. (2002). Qualitative Research \& Evaluation Methods (Vol. 3). California: Sage Publications, Inc.

Peters, J., Parletta, N., Lynch, J., \& Campbell, K. (2014). A comparison of parental views of their pre-school children’s ‘healthy’ versus ‘unhealthy’ diets. A qualitative study. Appetite, 76(0), 129-136. doi: 10.1016/j.appet.2014.02.001

Pliner, P. (1982). The Effects of Mere Exposure on Liking for Edible Substances. Appetite, 3(3), 283-290. doi: 10.1016/S0195-6663(82)80026-3

Pulley, C., Galloway, A. T., Webb, R. M., \& Payne, L. O. (2014). Parental child feeding practices: how do perceptions of mother, father, sibling, and self vary? Appetite, 80(0), 96-102. doi: 10.1016/j.appet.2014.05.001

Rollins, B. Y., Loken, E., Savage, J. S., \& Birch, L. L. (2014a). Effects of restriction on children's intake differ by child temperament, food reinforcement, and parent's chronic use of restriction. Appetite, 73(0), 31-39. doi: 10.1016/j.appet.2013.10.005 
Rollins, B. Y., Loken, E., Savage, J. S., \& Birch, L. L. (2014b). Measurement of food reinforcement in preschool children. Associations with food intake, BMI, and reward sensitivity. Appetite, 72(0), 21-27. doi: 10.1016/j.appet.2013.09.018

Schrodt, P., Witt, P. L., \& Messersmith, A. S. (2008). A meta-analytical review of family communication patterns and their associations with information processing, behavioral, and psychosocial outcomes. Communication Monographs, 75(3), 248-269. doi: 10.1080/03637750802256318

Seltzer, J.A. \& Bianchi, S. M. (2013). Demographic change and parent-child relationships in adulthood. Annual Review of Sociology, 39(1), 275-290. doi:10.1146/annurev-soc071312-145602

Sleddens, E. F. C., Kremers, S. P. J., Stafleu, A., Dagnelie, P. C., De Vries, N. K., \& Thijs, C. (2014). Food parenting practices and child dietary behavior. Prospective relations and the moderating role of general parenting. Appetite, 79(1), 42-50. doi:

10.1016/j.appet.2014.04.004

Smith, R., Monaghan, M., \& Broad, B. (2002). Involving young people as co-researchers: facing up to the methodological issues. Qualitative Social Work, 1(2), 191-207. doi: $10.1177 / 1473325002001002619$

Solér, C., \& Plazas, M. C. (2012). Integration of ethnic food into Swedish food rituals. The cultural fitness of tacos. Appetite, 58(3), 928-935. doi: 10.1016/j.appet.2012.02.010

Statistics Norway. (2013). Key figures for income and consumption. Retrieved 01.08.2014, from http://www.ssb.no/en/inntekt-og-forbruk/nokkeltall

Szczesniak, A. S. (1972). Consumer awareness of and attitudes to food texture II. Children and teenagers. Journal of Texture Studies, 3(2), 206-217. doi: 10.1111/j.17454603.1972.tb00624.x

Szczesniak, A. S. (2002). Texture is a sensory property. Food Quality and Preference, 13(4), 215-225. doi: 10.1016/S0950-3293(01)00039-8

Søndergaard, H. A., \& Edelenbos, M. (2007). What parents prefer and children like Investigating choice of vegetable-based food for children. Food Quality and Preference, 18(7), 949-962. doi: 10.1016/j.foodqual.2007.03.009

The Norwegian Directorate of Health. (2011). In Norwegian: Dietary advice to promote public health and prevent chronic diseases. Oslo: The Norwegian Directorate of Health. 
Tromsø municipality. (2014). Skolefritidsordning (SFO). Retrieved 01.08.2014, from http://translate.googleusercontent.com/translate_c?depth=1\&hl=no\&ie=UTF8\&prev= _t\&rurl=translate.google.com\&sl=no\&tl=en\&u=http://www.tromso.kommune.no/asto gefldataf.117151.36tba9a2.tct.html\&usg=ALkJrhieDYXR5ZCDK6ryahsBT6uFfPjPqw

van der Horst, K. (2012). Overcoming picky eating. Eating enjoyment as a central aspect of children's eating behaviors. Appetite, 58(2), 567-574. doi: 10.1016/j.appet.2011.12.019

van der Horst, K., Ferrage, A., \& Rytz, A. (2014). Involving children in meal preparation. Effects on food intake. Appetite, 79(1), 18-24. doi: 10.1016/j.appet.2014.03.030 Vollmer, R. L., \& Mobley, A. R. (2013). Parenting styles, feeding styles, and their influence on child obesogenic behaviors and body weight. A review. Appetite, 71(1), 232-241. doi: 10.1016/j.appet.2013.08.015

Wiggins, S. (2014). Adult and child use of love, like, don't like and hate during family mealtimes. Subjective category assessments as food preference talk. Appetite, 80(1), 7-15. doi: 10.1016/j.appet.2014.04.024

Zartler, U., \& Richter, R. (2012). My family through the lens. Photo interviews with children and sensitive aspects of family life. Children \& Society, 28(1), 42-54. doi: 10.1111/j.1099-0860.2012.00447.x

Zeinstra, G. G., Koelen, M., Kok, F., \& de Graaf, C. (2007). Cognitive development and children's perceptions of fruit and vegetables; a qualitative study. International Journal of Behavioral Nutrition and Physical Activity, 4(1), 30. doi: 10.1186/14795868-4-30 